\title{
PERSONALITY, ATTITUDES, AND AFFECT AS PREDICTORS OF SECOND LANGUAGE COMMUNICATION
}

\author{
PETER D. MACINTYRE \\ University College of Cape Breton \\ CATHERINE CHAROS \\ Oxford University
}

Numerous studies have established the importance of affective variables, such as attitudes, motivation, perceived competence, and anxiety, in predicting success in second language learning and communication. Path analysis was used to investigate the relations among these variables, to examine their impact on the frequency of second language communication, and to examine the role of global personality traits. Significant paths affecting the frequency of communication were found, from willingness to communicate in the second language (L2), language learning motivation, perceived L2 communicative competence, and the opportunity for contact with $L 2$ speakers. Further results demonstrate that global personality traits and language-related affective variables (such as attitudes and anxiety) set the psychological context for second language communication. These results are interpreted in terms of models of second language learning and communication.

Communication and second language acquisition are closely tied together. On one hand, recent trends toward a conversational approach to second language pedagogy reflect the belief that one must use the language to develop proficiency, that is, one must talk to learn. On the other hand, communication is more than a means of facilitating language learning, it is an important goal in itself. Whether the orientation for language learning stems from the desire to meet new people, travel, experience other cultures, or simply to use it in one's job

\footnotetext{
AUTHORS' NOTE: This research was supported by a postdoctoral fellowship from the Social Science and Humanities Research Council of Canada to the first author. The authors would like to express our gratitude to Richard Clément, $R$. C. Gardner, and the two anonymous reviewers for their invaluable comments on previous drafts of this manuscript. Portions of this study were presented at the annual conference of the Canadian Psychological Association in Charlottetown, PEI, Canada, June 1995. Correspondence related to this article should be addressed to the first author c/o University College of Cape Breton, PO Box 5300, Sydney, Nova Scotia, Canada B1P6L2, orbyE-mail to pmacinty@sparc.uccb.ns.ca.
} 
(Clément \& Kruidenier, 1986), the primary reason for language learning often is to use it to communicate. Unfortunately, research into these two topics, communication and second language learning, has developed along somewhat different lines.

This article draws upon models developed within these two streams of research in an attempt to predict the frequency of second language communication in a bilingual context. Predictor variables will be drawn from Gardner's (1985) socio-educational model of language learning and MacIntyre's (1994) model of willingness to communicate, adapted to refer to the second language. The major purpose of the present study will be to test this hybrid model using path analysis. Because both of the constituent models describe individual differences, a second purpose will be to examine the role of the global personality traits. Recent work on the Five Factor Model (e.g., Goldberg, 1993) suggests that it represents a taxonomy of global traits, and this development will be applied to the second language domain.

\section{SOCIO-EDUCATIONAL MODEL OF SECOND LANGUAGE (L2) LEARNING}

Individual differences in second language learning have been studied for several years. One of the most active and productive research programs has been undertaken by Gardner, Lambert, and their associates (Gardner \& Lambert, 1972). The emerging product of this research activity is the socioeducational model of second language acquisition (Gardner, 1985, 1988). Whereas portions of the model have been, and will continue to be, updated to incorporate new research results, the basic model has consistently been replicated (for a review, see Gardner, 1985; Gardner \& MacIntyre, 1992, 1993b).

The socioeducational model (Gardner, 1985) proposes that two basic attitudes -integrativeness and attitudes toward the learning situation-arise from the learners' sociocultural milieu. Integrativeness refers to the desire to learn a second language to meet and communicate with members of the target language community. Attitudes toward the learning situation refer to the evaluation of the language teacher and the course. Both integrativeness and attitudes toward the learning situation contribute to the learners' level of motivation. This tripartite cluster, shown in Figure 1, has been called the integrative motive (Gardner, 1985). Integrative motivation, in turn, influences the activity level of the learner in learning situations, including both formal (e.g., classroom) and informal (e.g., on the street) types of learning. Much of the research on the socioeducational model has examined the role of motivation in language leaning and demonstrates its importance in producing individual differences in various forms of language learning achievement (Gardner, 1980, 1985, 1988; Gardner \& MacIntyre, 1992, 1993a). 


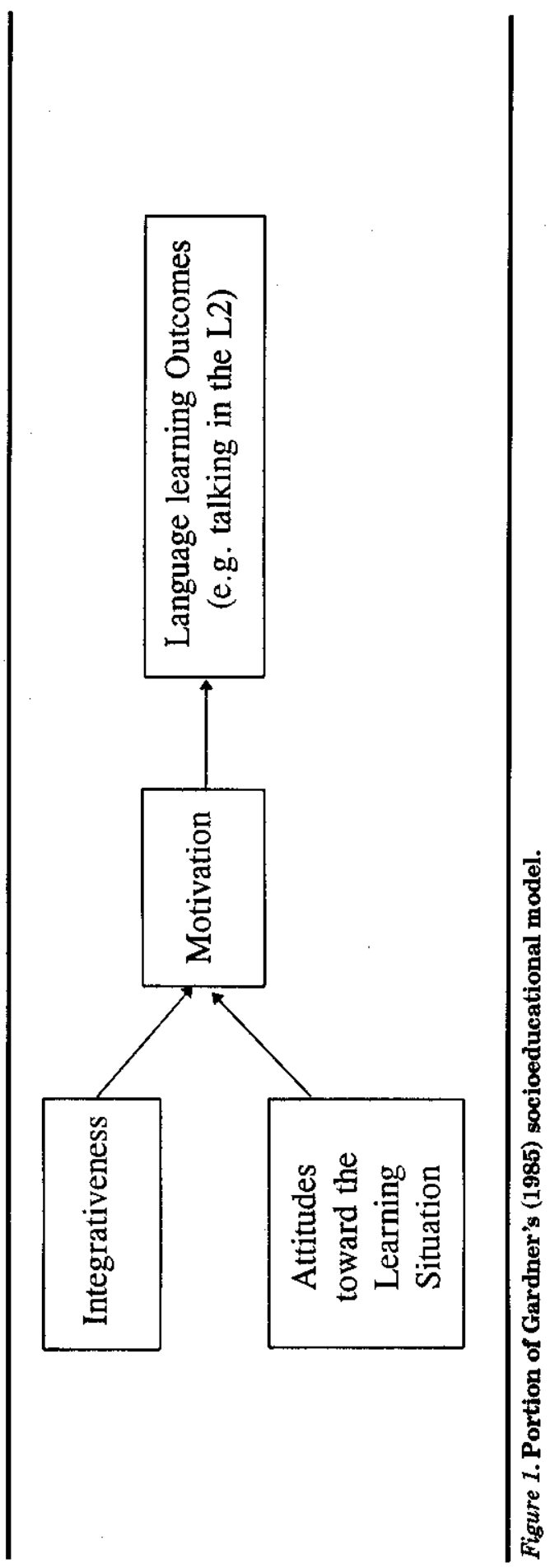


Research has shown that in addition to attitudes and motivation, anxiety about second language communication has a significant effect on second language learning (Horwitz, Horwitz \& Cope, 1986; Horwitz \& Young, 1991; MacIntyre \& Gardner, 1991b, 1994b). Language anxiety, which is the situation-specific apprehension generated in second language contexts, has been shown to correlate negatively with second language course grades (Horwitz, 1986) and the ability to take in, process, and output second language information (MacIntyre \& Gardner, 1994a, 1994b). With respect to communicating, it has been shown that speaking in the second language can be especially anxiety provoking (Horwitz et al., 1986; Koch \& Terrell, 1991; MacIntyre \& Gardner, 1991c). Gardner and MacIntyre (1993a) found that among attitudes, motivation, and anxiety, measures of language anxiety showed the strongest correlations with several indexes of second language achievement.

In a theoretical discussion of the relation between language anxiety and motivation, Gardner and MacIntyre (1993b) proposed reciprocal paths between motivation and language anxiety; high levels of motivation are likely to abate anxiety, and high levels of anxiety are likely to inhibit motivation. Although this relation has been suggested, and the available data show a negative correlation between language anxiety and motivation, language anxiety has not been consistently included as a variable in tests of Gardner's socioeducational model (MacIntyre \& Gardner, 1991b). Having measures of both language anxiety and integrative motivation in the present study will allow for an examination of the connection between them.

\section{WILLINGNESS TO COMMUNICATE}

Whereas the study of anxiety in second language communication is emerging as an important topic in the literature, native language communication apprehension has been widely studied for many years (Richmond \& McCroskey, 1985). Communication apprehension is conceptually similar to language anxiety; they both refer to anxiety about communicating (see Daly, 1991; Horwitz et al., 1986). Research on communication apprehension in the native language has shown its potentially detrimental effects on the frequency and quality of communication (Beatty, 1988; McCroskey, 1977, 1984; McCroskey \& Richmond, 1987).

One of the strongest, most reliable effects of communication apprehension is a reduced desire to communicate (Beatty, 1987). Recently, McCroskey and associates (McCroskey, 1992; McCroskey \& Baer, 1985; McCroskey \& McCroskey, 1986; McCroskey \& Richmond, 1991) have proposed a construct, "willingness to communicate," that captures the 
major implications that concepts like communication apprehension, introversion, reticence, and shyness have for communicative behavior. Willingness to communicate is defined as a stable predisposition toward communication when free to choose to do so (McCroskey \& Baer, 1985). A person may be unwilling to communicate for a variety of reasons, such as anxiety, introversion, alienation, or a lack of communicative competence, for example. All of these variables have shown significant correlations with willingness to communicate (Burgoon, 1976; McCroskey \& Richmond, 1991; McCroskey, Richmond, \& McCroskey, 1987).

MacIntyre (1994) developed a path model to predict willingness to communicate in the native language (see Figure 2). The model postulates that higher levels of willingness to communicate are based on a combination of greater perceived communicative competence and a relative lack of communication apprehension. The model further shows the influence of personality traits (see also McCroskey, 1984; McCroskey \& Baer, 1985). The global trait of introversion contributes to both communication apprehension and the perception of communicative competence, and self-esteem was found to play a role in developing communication apprehension. Finally, the model incorporates Burgoon's (1976) suggestion that societal pressures, reflected in feelings of alienation and anomie, play a role in generating an unwillingness to communicate. One avenue available for further exploration is the impact of different situational contexts on the model. MacIntyre (1994) recommended exploring the interaction between personality and specific situational characteristics in their influence on willingness to communicate (p. 140). Situations in which a communicator uses his or her second language represent an opportunity to both test the model and integrate it with existing language learning research.

Thus the willingness to communicate model will be applied to second language communication. In fact, its two key variables, anxiety about communication and the perception of communicative competence, have consistently appeared as correlates of second language proficiency (Clément, Gardner, \& Smythe, 1977, 1980; MacIntyre, 1992). In his contextual model, Clément $(1980,1986)$ considers them to form a higher order construct, self-confidence, that provides increased motivation for second language learning and contact (communication) with the target language community. Whereas Clément's model treats selfconfidence as a unitary construct, MacIntyre's (1994) model postulates a specific relation between its major components, specifically that anxiety influences the perception of competence. In support of this hypothesis, MacIntyre and Noels (1994) found that anxious language learners tended to underestimate, and relaxed students to overestimate, their ability to speak and comprehend the second language as evaluated by independent, bilingual raters. 


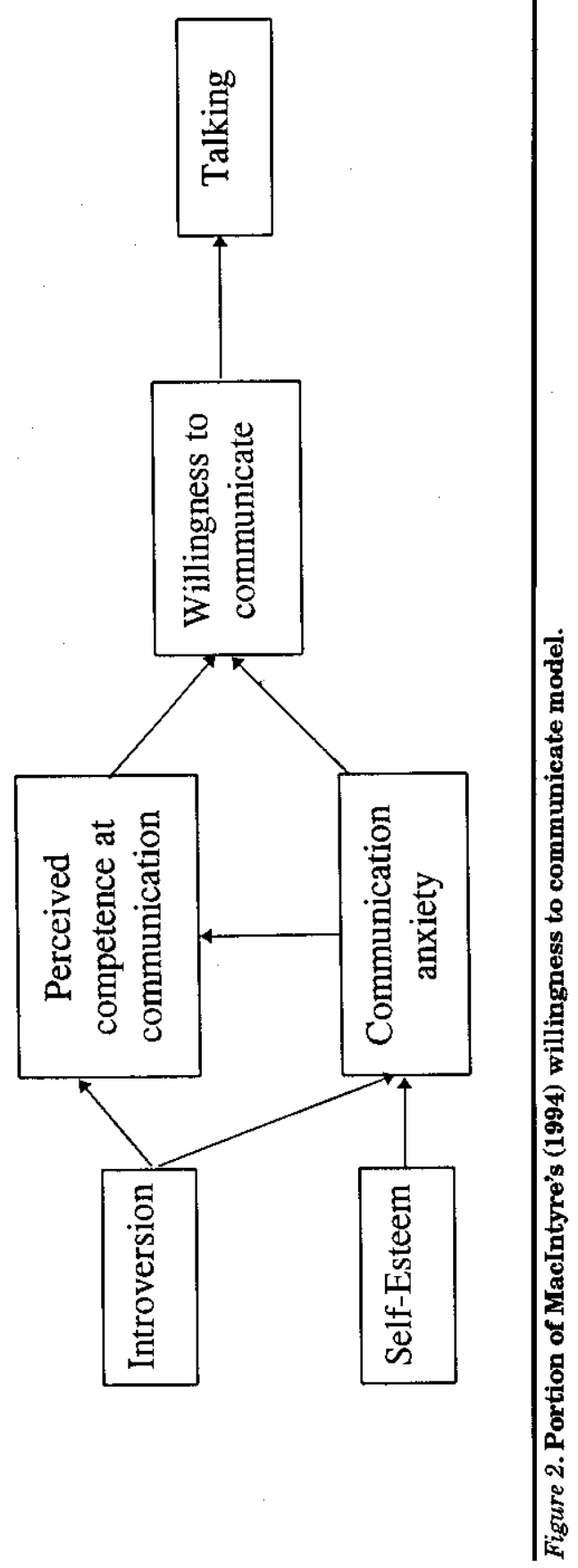




\section{GLOBAL PERSONALITY TRAITS}

As noted above, the influence of global personality traits (see Funder, 1991) has been examined in the research on willingness to communicate. Also, some research has been conducted on the role of personality traits in second language learning. Although personality traits are hypothesized to be important in language acquisition (Gardner, 1991), past research in this area has produced inconsistent results (Lalonde \& Gardner, 1984; Skehan, 1989).

Introversion-extroversion has been the trait of primary interest and, across several investigations, has produced inconsistent relations with a variety of measures of language achievement (Chastain, 1975; Naiman, Frolich, Stern, \& Todesco, 1978; Pritchard, 1952; Smart, Elton, \& Burnett, 1970; Swain \& Burnaby, 1976). In considering this ambiguity, Skehan (1989) notes that for academic achievement in general, introversion is usually the more desirable end of the trait dimension. But for language learning, the desirable end may be either extroversion or introversion, depending on the learning context or instructional methods. For example, language learning based in a formal classroom setting emphasizing rote memory for vocabulary and grammar rules might favor the introvert; language learning based on communication would likely favor the extrovert. In general, the correlation between extroversion and language achievement has been nonsignificant or slightly positive and the results seem to be tied to the particular measures employed in the studies (Skehan, 1989). Studies focusing on other personality variables have also yielded mixed results.

Lalonde and Gardner (1984) attempted to incorporate personality variables into the socioeducational model. Eighteen personality variables were included, but they showed very few correlations with language achievement, aptitude, or perceived second language competence. However, integrativeness, motivation, and attitudes toward the learning situation did show significant correlations with two post hoc groupings of personality traits that were tentatively labelled as analytic orientation and seriousness. Used in a causal model predicting language achievement, analytic orientation was found to underlie integrativeness, and seriousness was related to attitudes toward the learning situation. Lalonde and Gardner concluded that broad personality traits have only an indirect effect on second language achievement, an effect channeled through language-related attitudes and motivation.

The study of personality provides no shortage of theoretical models from which to choose or levels at which to conceptualize traits. The strategy used by Lalonde and Gardner (1984) in grouping traits based on factor analysis implies that among the 18 traits that they measured, more basic personality traits exist. A similar rationale has been employed by researchers using factor analysis to investigate the Five Factor Model (or Big-Five; see Goldberg, 1993). This 
"model" is intended to represent a taxonomy of the most basic, global personality traits. Whereas various versions of the Five Factor Model have been reported (Digman, 1980; McCrae \& Costa, 1989; Norman, 1963), their structure and interpretation are remarkably consistent (Goldberg, 1993). This emerging consensus on the basic personality factors may renew interest in the study of the role of personality factors in language learning.

Using Goldberg's (1992) terminology for the Big-Five, the first trait, labelled introversion-extroversion, contrasts reserved, quiet, and unassertive with outgoing, talkative, and active. The second factor is labelled pleasantness or agreeableness and contrasts cold, selfish, and distrustful with kind, cooperative, and generous. The third trait, conscientiousness or dependability, contrasts disorganized, careless, and lazy with responsible, thorough, and hardworking. The fourth trait, emotional stability, contrasts tense, nervous, and unstable with calm, contented, and unemotional. The final factor, intellect or sophistication, contrasts analytical, imaginative, and creative with unintelligent, unreflective, and uninquisitive. This final trait has also been labelled as culture or openness to experience and may best be seen to reflect the degree of a search, tolerance, and appreciation for the unfamiliar (Costa \& McCrae, 1985).

The present study attempts to combine the work on language learning, willingness to communicate, and global personality traits. The primary purpose of this study is to test the ability of a hybrid of Gardner's (1985) socioeducational model and MacIntyre's (1994) willingness to communicate model to predict the frequency of using the second language in daily interactions. This combined model will be tested using path analysis. A second purpose will be to examine the influence of global traits that will be integrated into the model in ways that are consistent with previous research.

The initial model is shown in Figure 3. The major elements of Gardner's (1985) model and their interrelations are shown: Integrativeness and attitudes toward the learning situation are independent, and both contribute to motivation for language learning. The model also shows the relations among elements of MacIntyre's (1994) model: Language anxiety reduces perceived communicative competence, and both of these variables influence willingness to communicate. Consistent with Clément's $(1980,1986)$ contextual model, a path from willingness to communicate to motivation is proposed. Both willingness to communicate and motivation for language learning contribute to determining the frequency of second language communication.

The model also shows the influence of personality traits. It is possible to speculate on a large number of potential paths involving these variables. Based on Lalonde and Gardner's (1984) suggestions, the influence of the Big-Five is expected to operate indirectly, via attitudes, motivation, language anxiety, and perceived competence. As 
described below, there is some reason to expect that each of the Big-Five traits may play a role in second language communication, and specific paths were proposed prior to the study (as shown in Figure 3). For the sake of parsimony, each trait was assigned only one predicted path.

Language students who are higher in intellect may perceive themselves as more knowledgeable persons and also more competent in the second language (see Clément \& Kruidenier, 1986), thus a path from intellect to perceived second language communicative competence is proposed. Extroverts' preference for social activity may lead them to have lower levels of language anxiety about social interaction using the L2 (MacIntyre \& Noels, 1994; Skehan, 1989), therefore a path from extroversion to language anxiety is proposed. People with higher levels of agreeableness, who are more pleasant, likely will anticipate more positive interaction with members of the second language group (see Clément, 1980). The most likely variable to be affected by this seems to be integrativeness, thus a path is proposed from agreeableness to integrativeness. Individuals with lower emotional stability may be more prone to language anxiety. However, a path from emotional stability to language anxiety is not explicitly proposed here because prior research has demonstrated that language anxiety is not strongly related to general trait anxiety, which would be reflected in a lack of emotional stability. A path is expected between emotional stability and integrativeness. This is based on Segalowitz's (1976) finding that those who have less positive attitudes toward the target language group also feel uncomfortable speaking to a member of that group. Finally, conscientiousness also may play a role in that those who are better organized may approach language learning in a more systematic manner and may show better cognitive processing of language instruction (Krashen, 1981; Lalonde \& Gardner, 1984). Therefore, a path from conscientiousness to attitudes toward the learning situation is proposed.

Figure 3 shows one additional element. As noted by Clément (1980, 1986), the sociolinguistic context plays a potentially important role in providing the opportunity for frequent and/or pleasant L2 contact. MacIntyre (1994) also proposed that studies examine the influence of situations on willingness to communicate, as did the work of Burgoon (1976). Therefore, a measure of the language context, as defined by a self-report of the relative concentration of L1 and L2 at home and at work, will be included as an exogenous variable in the model. Based on Clément's (1980, 1986) model, context is expected to influence willingness to communicate because it follows from Clément's description that self-confident individuals will be more willing to communicate in the second language. Further, a direct path from context to frequency of communication is proposed because the number of opportunities to communicate in the second language should influence the frequency of doing so. 


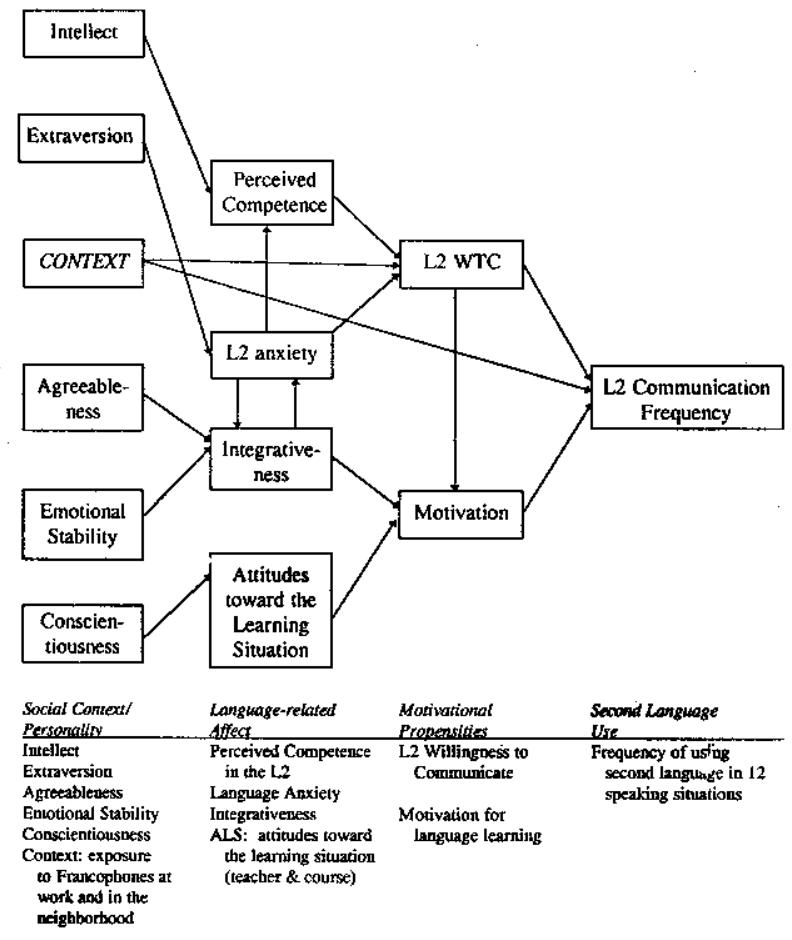

Figure 3. Base path analysis model to be tested.

The purpose of the present study is to examine the relations within and between the language learning and communication models cited above, and to extend the models by testing their ability to predict in vivo language use. In addition, the somewhat neglected issue of personality dispositions that favor second language acquisition and use will be examined.

\section{METHOD}

\section{PARTICIPANTS}

This study was conducted in Ottawa, which is a large, bilingual (FrenchEnglish) city. Ninety-two Anglophone students, taking introductorylevel conversational French, were recruited from adult evening classes offered by local school boards. Thirty of the participants were male (mean age $=32.6, S D=12.3$ ) and 62 were female (mean age $=33.8, S D=12.0$ ). All of the participants spoke English as their 
native language and, as a group, possessed only a minimal level of French competence.

\section{MATERIALS}

The materials required for this study included self-report measures of the Big-Five personality traits, frequency of communication, willingness to communicate, perceived competence, attitudes, motivation, and the amount of French present in the work and home context. The measures chosen here were selected to be brief but sound psychometric instruments. The limited time available for testing (30-45 minutes) did not permit the use of longer instruments. The scales were presented in one of eight random sequences. A description of these scales, an example item, and the Cronbach alpha coefficient $(\alpha)$ for the present sample are as follows:

\section{Measures of Language Learning Affect}

A series of brief measures of attitudes, motivation, and anxiety were administered. All ratings were made on a 7-point Likert-type scale. Gardner and MacIntyre (1993a) have shown that these "Guilford-style" items have acceptable convergent and predictive validity.

1. Integrativeness $(\alpha=86$ ). This measures the degree to which respondents were learning French for the purpose of interacting and communicating with Francophones. This aggregate measure was composed of three single-item measures of integrative orientation, attitude toward French Canadians, and interest in foreign languages. An example item is "My feelings about learning French in order to interact with French Canadians are: Weak-Strong."

2. Motivation $(\alpha=.65)$. Motivation was measured with three single-item measures of the desire to learn French, motivational intensity (effort), and attitude toward learning French. An example item is "If I were to rate how hard I work at learning French, I would characterize it as: Very Much-Very Little."

3. Attitudes toward the learning situation $(\alpha=.89)$. This was measured by two items, attitude toward the French teacher and attitude toward the course. An example item is "My attitude toward my French course is: Unfavorable-Favorable."

4. Language anxiety $(\alpha=.48) .{ }^{1}$ This was also measured by two items, one assessing French classroom anxiety and the other measuring French use anxiety. An example item is "My anxiety when speaking French is: Low-High."

\section{Communication-Related Variables}

The following three variables were adapted to refer to communication using French. Each of the measures presents 12 communication 
contexts involving speaking to friends; acquaintances, and strangers in four settings: dyads, small groups, formal meetings, and public speaking situations.

1. Perceived competence in French $(\alpha=.98)$. Twelve items, adapted from McCroskey, Richmond, and McCroskey (1987), assessed the average percentage of time, ranging from $0 \%$ to $100 \%$, that respondents felt competent in using French to speak in 12 situations. An example is "talk in a small group of friends."

2. Frequency of communication in French $(\alpha=.97)$. Items from the perceived competence scale were adapted to measure the frequency of communicating in French for each of 12 situations, using a 7-point scale with the anchors never and many, many times. The potential range of scores was 0 to 72 . An example item is "talk with an acquaintance."

3. Willingness to communicate in French $(\alpha=.97)$. Twenty items from McCroskey \& Baer (1985) assessed the average percentage of time, ranging from $0 \%$ to $100 \%$, that respondents would choose to communicate in French in various situations. In addition to the 12 speaking contexts noted in items number 1 and number 2 immediately above, 8 "filler" items were also included. An example is "talk to a service station attendant."

\section{Personality Measure}

Goldberg's (1992) transparent bipolar scale was used to assess five global personality traits. Goldberg (1992) argues that the transparent bipolar inventory is an acceptable substitute for a longer scale of the Big-Five (such as the NEO-PI). Seven items on a 9-point semantic differential scale were used to measure each of the following personality traits:

1. Extroversion (vs. introversion) $(\alpha=.85)$. An example item is silenttalkative.

2. Agreeableness (vs. disagreeableness) ( $\alpha=.63$ ). An example item is cooperative-uncooperative.

3. Conscientiousness (vs. negligence) $(\alpha=74)$. An example item is disorganized-organized.

4. Emotional stability (vs. neuroticism) ( $\alpha=.56)$. An example item is relaxed-tense.

5. Intellect (vs. unsophisticated) $(\alpha=.77)$. An example item is creativeuncreative.

\section{Social Context}

This measure was written specifically for this investigation.

1. Context $(\alpha=.60)$. The degree to which respondents encounter French in their neighborhoods and in their workplace was assessed using single items with 5 -point scales. The labels assigned to the 5 points were $(1=$ all English, no French; 2 = mostly English, some French; $3=$ half English, half French; 4 = some English, mostly French; and $5=$ no English, all 
French). The context variable is the sum of the ratings of the amount of French encountered at work and at home. The rating for the people who indicated that they did not work outside the home $(n=17)$ was obtained by doubling their rating of the home context on the assumption that these individuals are, in effect, working at home.

\section{PROCEDURE}

The boards of education offering adult evening classes were contacted about the procedures for this study. A list of 12 instructors of introductory-level French-as-a-second-language courses was provided. These instructors were then contacted by phone and asked for their cooperation in contacting and testing students during class time. Eight instructors participated, 3 could not be reached by phone within the time frame set for the study, and 1 was unable to relinquish class time for testing. With the permission of the instructors, all classes were tested over a 2-week period, near the end of their courses. As the students arrived for class, they were informed that a research study of second language communication was being conducted and that participation was voluntary. They were then presented with a consent form that summarized the procedures of the study, described the types of measures being used, and noted that the data would be collected anonymously. Almost all students decided to participate (90 to 95\%), and respondents were given as much time as required to complete the questionnaire, less than 45 minutes in all cases.

\section{RESULTS AND DISCUSSION}

A path analysis, using a maximum likelihood solution from LISREL VII (Jöreskog \& Sörbom, 1989), was conducted on the correlation matrix shown in the appendix. ${ }^{2}$ The base model shows a reasonable fit to the data, although the chi-square is significant $\left(\chi^{2}(46)=187.2\right.$, $p<.001$ ). Twelve of the 15 path coefficients in the initial model were significant $(t>2.0)$. All of the paths that were derived from the Gardner (1985) and MacIntyre (1994) models were replicated, including the proposed effects on the frequency of L2 communication. In addition, 4 of the 5 predicted paths involving the global personality traits were obtained, as were both paths involving social context. The only nonsignificant paths were from agreeableness to integrativeness, integrativeness to language anxiety, and willingness to communicate to motivation. It should be noted that all 3 of these paths were based on speculations about the relations among the variables and had not been tested explicitly in prior investigations. It would be inappropriate, however, to conclude that these variables are not at all related to each other, because 
that would amount to accepting the null hypothesis. Therefore, we will not speculate on the reasons for the absence of these paths.

The significant chi-square test for the base model indicates that additional variance could be accounted for if new paths were added. Strictly speaking, adding additional paths is an exploratory procedure (MacCallum, Roznowski, \& Necowitz, 1992), as opposed to the confirmatory approach adopted up to this point. Such paths should be regarded as "data driven" and therefore tentative, pending replication. Nevertheless, the major value of such results may be to provide potentially interesting avenues for future investigations. Therefore, additional paths were added, one at a time, until the chi-square became nonsignificant. LISREL modification indexes, which express the extent to which chi-square would be reduced by adding an additional path, were employed in this procedure. At each step, the path with the highest modification index was added. Finally, the three nonsignificant paths were removed before the final model was evaluated. The sequence of steps taken to revise the model is shown in Table 1 . The standardized solution for the final model is shown in Figure 4.

The last variable in the causal chain is frequency of second language communication. Four significant, positive paths were obtained for this variable: ones leading from willingness to communicate, motivation, perceived communicative competence, and context. These results confirm paths suggested by Gardner's (1985) socioeducational model as well as MacIntyre's (1994) model of willingness to communicate (see also McCroskey, 1992), as shown in Figure 3. In the case of motivation, students who have greater motivation for language learning report using the language more frequently. In the case of willingness to communicate, students who are more willing to communicate will be more likely to do so. Further, having the opportunity to converse with Francophones, reflected in the context variable, also plays a role. The largest single effect was obtained for perceived communicative competence. This is reasonable because all of the respondents were at a relatively low level of actual competence. This might suggest that simply perceiving that one has the ability to communicate, regardless of one's actual proficiency, can affect the rate of participation in L2 conversation.

Underlying motivation for language learning in Gardner's socioeducational model are integrativeness and attitudes toward the learning situation (Gardner, 1985). The present results replicate Gardner's tripartite division of the integrative motive. A significant path was also found from integrativeness to attitudes toward the learning situation. Using different exogenous variables and measurement techniques, and in a unilingual context, Gardner, Lalonde, and Pierson (1983) showed the opposite path between these two constructs. In the present study, frequent contact with the L2 group is a constant possibility, therefore integrativeness likely would be a much more stable attitude than attitudes toward the learning situation. This may explain why 
Table 1

Step-By-Step Procedure for Revising the Model to Add Data-Driven Paths

\begin{tabular}{|c|c|c|c|c|c|c|}
\hline Model & $x^{2}$ & $d f$ & GFI & $\begin{array}{l}\text { Adj. } \\
\text { GFI }\end{array}$ & RMSR & $\chi^{2 / d f}$ \\
\hline Base model & 187.2 & 46 & .81 & .63 & .151 & 4.07 \\
\hline $\begin{array}{r}\text { Revision 1: } \\
\text { Add a path from } \\
\text { integrativeness to attitudes } \\
\text { toward the learning situation }\end{array}$ & 137.85 & 45 & .86 & .79 & .109 & 3.06 \\
\hline $\begin{array}{r}\text { Revision 2: } \\
\text { Add a path from } \\
\text { perceived competence to } \\
\text { frequency of communication }\end{array}$ & 77.17 & 44 & .90 & .82 & .087 & 1.75 \\
\hline $\begin{array}{r}\text { Revision 3: } \\
\text { Add a path from context to } \\
\text { perceived competence }\end{array}$ & 62.00 & 43 & .92 & .84 & .073 & 1.44 \\
\hline $\begin{array}{r}\text { Revision 4: } \\
\text { Add a path from } \\
\text { agreeableness to willingness } \\
\text { to communicate }\end{array}$ & 53.28 & 42 & .93 & .84 & .061 & 1.27 \\
\hline $\begin{array}{l}\text { Final model: } \\
\text { Erase all nonsignificant paths }\end{array}$ & 55.75 & 45 & .92 & .84 & .067 & 1.24 \\
\hline
\end{tabular}

Note: GFI = goodness of fit index; Adj. GFI = adjusted goodness of fit index; RMSR = root mean square residual.

the path from integrativeness to attitudes toward the learning situation emerged in the present study.

The hypothesized causes of willingness to communicate were replicated (MacIntyre, 1994). In this case, both language anxiety and perceived competence exerted a direct influence on willingness to communicate, and the predicted effect of anxiety on perceived communicative competence was also supported. Also, the path from context to willingness to communicate indicates that increased opportunities for interaction directly affect one's willingness to communicate in the L2. Thus we suggest that the intention or willingness to engage in L2 communication is determined by a combination of the student's perception of his or her second language proficiency, the opportunity to use the language, and a lack of apprehension about speaking.

At the far left of Figure 4 are the exogenous variables: the five personality factors and the measure of social context. With respect to context, having more opportunities for interaction in French may lead to an increase in perceived competence, a greater willingness to communicate in French, and more frequent communication. The path leading to perceived competence suggests that the opportunity to communicate leads to the development of greater actual competence, likely through a combination of practice and the adjustment of learner beliefs. Obviously, the learners' ability to communicate in the L2 will improve with practice. But this path might also indicate that exposure 


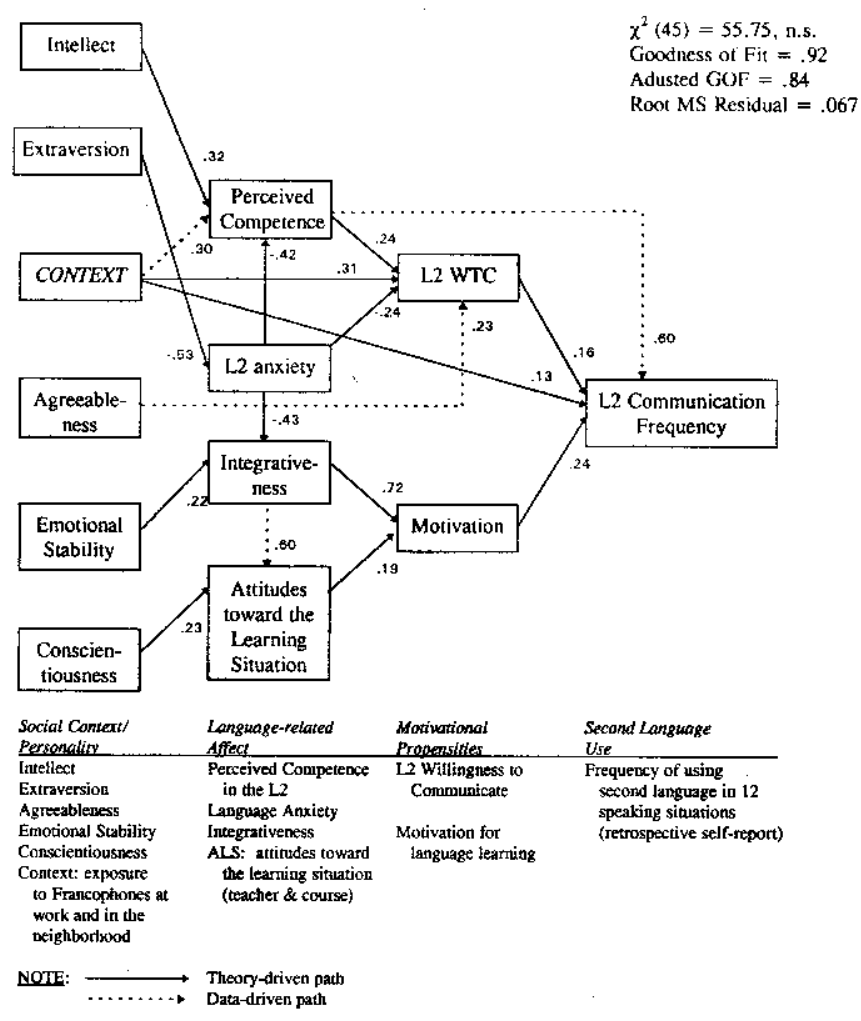

Figure 4. Final model showing all significant paths.

to authentic oral input reduces the formality (e.g., proper grammar rules) that some students experience in the language classroom. Perhaps the perception of competence increases because the level of objective L2 competence required for daily communication is shown to be lower than expected. For example, students may learn effective verbal (e.g., requesting synonyms for unfamiliar words, switching to L1 sometimes) and nonverbal strategies (e.g., using gestures and facial expressions to convey meaning) to avoid conversational trouble spots (see Oxford, 1991). This path is data driven, and this proposed explanation might make an interesting avenue for future investigation.

The global personality traits each showed a significant path in the present model. The measure of intellect was found to underlie perceived competence, as predicted. It would appear that persons who consider themselves to be more intellectual, sophisticated, or open to experience (synonyms for this factor according to Goldberg, 1993), also see themselves as more competent in French.

Extroversion, as predicted, showed a negative effect on language anxiety. In most situations, it is not necessarily the case that extroverts 
should feel less nervous than introverts, because extroversion reflects sociability rather than emotional arousal (Goldberg, 1993). Within the language domain, both a significant path from extroversion to language anxiety coupled with the lack of a path from emotional stability are consistent with MacIntyre \& Gardner's (1989, 1991a) findings that general trait anxiety, as would be reflected in the emotional stability factor, is not typically associated with language anxiety. This supports the assertion that it is the social and communicative demands of L2 interaction, and not a predisposition to nervousness, that drive language anxiety.

Asignificant path was also obtained leading from agreeableness, but not to its predicted destination of integrativeness. Instead, a datadriven path was found from agreeableness to willingness to communicate. People who are more pleasant and agreeable themselves would be more likely to have pleasant contacts with target language group members, and this appears to be reflected in their willingness to communicate. Clément $(1980,1986)$ suggests that frequent, pleasant contact with members of the target language community will primarily determine the level of linguistic self-confidence, a construct very similar to willingness to communicate. We might suggest that whereas self-confidence leads to a motivation for language learning, willingness to communicate is based on a preparedness for language use, as if sufficient competence had already been achieved for the communicative purpose at hand. Expressed in terms of path analysis, in a future study, we would expect a path from self-confidence to motivation for language learning, but not one from willingness to communicate to motivation. This hypothesis must be considered tentative but would indicate a difference between self-confidence and willingness to communicate.

As predicted, a significant path was obtained leading from emotional stability to integrativeness. As noted above, this factor reflects a type of trait anxiety, and people who feel less anxious appear to be more disposed to interacting with members of the second language community. Segalowitz (1976) found that people who were more nervous speaking to a member of another language group had less positive attitudes toward them. This may be attributable to a process of self-perception (Bem, 1972; Fazio, 1987) whereby individuals perceive their own anxiety and decide that there must be something about the language group that is making them nervous. Therefore that group is perceived as less likable and this would be reflected in a reduced level of integrativeness.

The final exogenous variable to show a significant path was conscientiousness. It was hypothesized, based on Lalonde and Gardner (1984) and Krashen (1981), that students who were better organized might show more positive attitudes toward the learning situation. We speculate that success in a structured course, as opposed to language acquisition "on the street," might be more dependent on the student's 
level of organization and attention to detail. Thus students who are more conscientious and well organized, as compared to less well organized ones, may possess an advantage in study habits that leads to a more positive attitude toward the language course.

Considering the final model as a whole, we have not obtained any recursive paths, all of the relations are shown as one-way. This reflects our desire to develop a model that predicts the frequency of L2 communication at a given time. There is no doubt that, over time, as students continue to learn and use the second language, changes in other variables should be expected. For example, Clément's $(1980,1986)$ contextual model clearly states that frequent and pleasant interethnic contact will influence anxiety and the perception of competence. Whereas the model shown in Figure 4 does not include paths from L2 communication backward to other variables, we can be certain that a longitudinal study would show recursive relations.

\section{CONCLUSIONS}

This study attempted to integrate a number of issues that arise in reference to second language learning and communication. The major purpose of the investigation was an attempt to replicate relations described in a model of language learning motivation and a model of willingness to communicate, and to assess interrelations between those models. The major elements of Gardner's (1985) socioeducational model show the expected relations with each other and with frequency of L2 communication. As well, the willingness to communicate construct appears to adapt well to the second language context and may represent a profitable addition to this literature. Two of the three expected paths between the two models were not supported in this data set. The present analysis suggests that communicating in a second language, in a bilingual milieu, among beginning language students, appears to be related to a willingness to engage in L2 communication, motivation for language learning, the opportunity for contact, and, perhaps most important, the perception of competence. In turn, language anxiety, intellect, and the social context were shown to influence the perception of $\mathrm{L} 2$ competence in this group. The diversity of influences (social, personality, and affective) converging on these variables shows the complexity involved in L2 communication.

The second purpose of this study was to examine the potential role of global personality traits, as identified in the Five Factor Model, in the hybrid model. Based on the present results, it would appear that global personality traits are implicated indirectly, via their influence on language-related attitudes, language anxiety, perceived L2 competence, motivation for language learning, and willingness to communicate. The contribution of both personality traits and social context to 
predicting the frequency of L2 communication is clearly evident in the present study.

It should be noted that the model emerging from this investigation contains both exploratory and replicated paths. One of the values of the exploratory paths identified in this model is to offer suggestions for future research. Such investigations might examine the relations among willingness to communicate, motivation, and self-confidence, in particular to consider whether willingness to communicate lacks the motivational properties implied by the self-confidence construct. Perceived competence exerted a direct and strong influence on the frequency of communication in this group of beginning students. Future research might consider whether the effect is as strong among students with more language training. The path from integrativeness to attitudes toward the learning situation was reversed from that obtained in an earlier study by Gardner et al. (1983). If this path replicates, future research might investigate whether this is a function of the social milieu, the nature of the language course in which the subjects were enrolled, or the obtained level of second language competence. Finally, willingness to communicate was influenced by four direct paths, including one from the agreeableness trait, and indirect paths from extroversion and intellect. In light of these findings, research on native language willingness to communicate might examine the interaction of global traits in producing a willingness to communicate.

Future research might also examine the degree to which the present model replicates within various groups and across social contexts. The meaning of bilingualism and second language communication may depend on the relations between language groups involved. Whether the same model can be applied to both minority and majority groups learning each others' language would be an interesting avenue for further study (see Clément, 1986). Also, the potential for the model to show gender differences should be explored. Finally, it should be noted that the frequency of communication was measured using self-report. Although there is evidence that willingness to communicate is significantly correlated with observed communicative behavior (Zakahi \& McCroskey, 1989), the link with overt behavior must be well established.

In spite of the need for future research and the limitations of the present study, this investigation has demonstrated that models of second language acquisition can be integrated successfully with those from the communication domain. In addition, both global personality traits and social context have an impact on the process of using a second language. These areas are often isolated from each other, and their synthesis shows that potentially powerful models can emerge from the convergence of knowledge in various domains. In terms of predicting the frequency of second language communication, the present study clearly shows that it is a complex process indeed. 


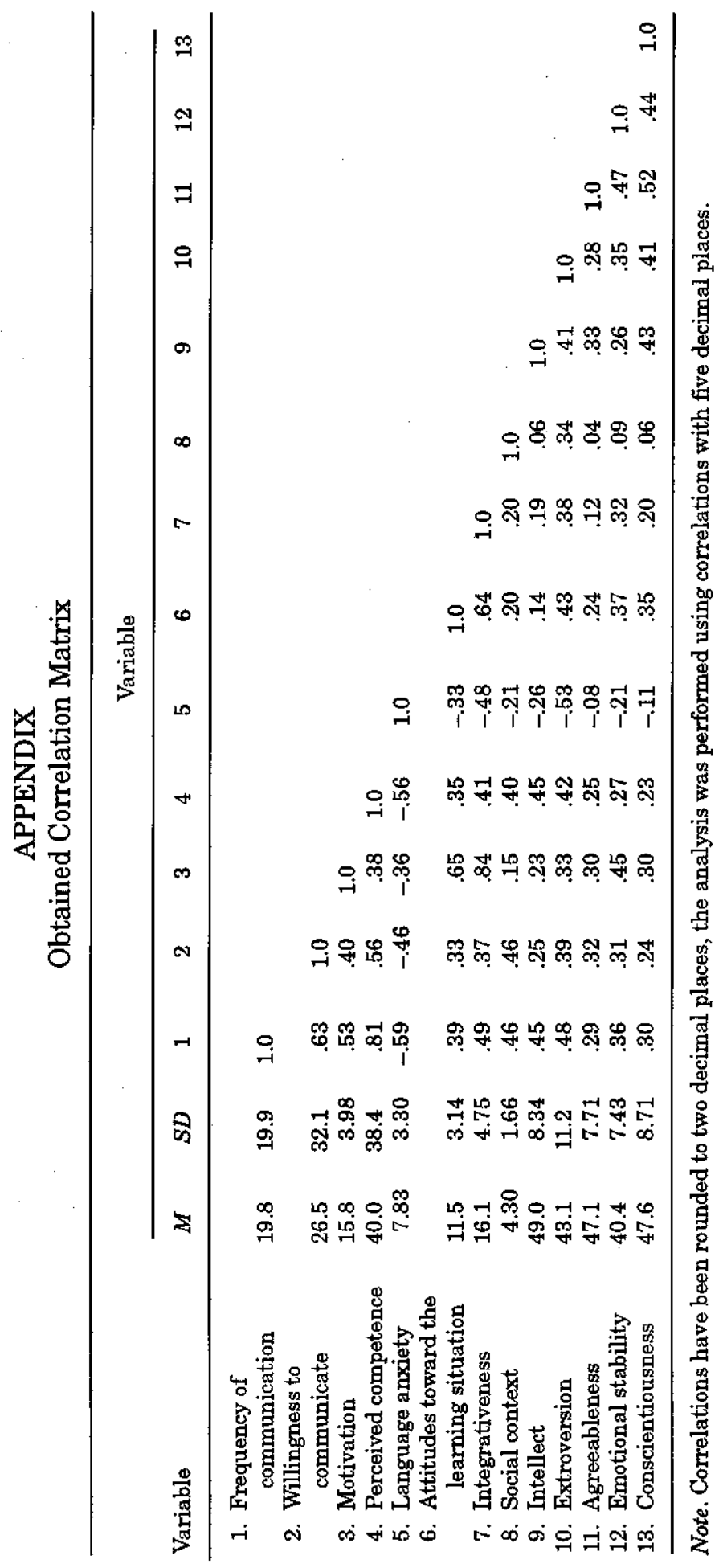




\section{NOTES}

1. The coefficient alpha for some of these measures, particularly language anxiety, is low. The alphas for motivation, agreeableness, emotional stability, and the measure of context also are somewhat lower than desirable. This may result from attempting to measure a broad domain with a small number of scale items. As a result, some of the path coefficients involving these variables may be attenuated.

2. Path analysis was selected instead of a latent variable analysis because two of the constructs, context and language anxiety, would have only two observed indicator variables. In cases where only two observed variables define a latent construct, an indeterminate solution may arise.

\section{REFERENCES}

Beatty, M. J. (1987). Communication apprehension as a determinant of avoidance, withdrawal and performance anxiety. Communication Quarterly, 35, 202-217.

Beatty, M. J. (1988). Situational and predispositional correlates of public speaking anxiety. Communication Education, 37, 28-39.

Bem, D. J. (1972). Self-perception theory. In L. Berkowitz (Ed.), Advances in experimental social psychology (Vol. 6, pp. 1-62). San Diego, CA: Academic Press.

Burgoon, J. K. (1976). The unwillingness to communicate scale: Development and validation. Communication Monographs, 43, 60-69.

Chastain, K. (1975). Affective and ability factors in second language acquisition. Language Learning, 25, 153-161.

Clément, R. (1980). Ethnicity, contact and communicative competence in a second language. In H. Giles, W. P. Robinson, \& P. M. Smith (Eds.), Language: Social psychological perspectives (pp. 147-154). Oxford, UK: Pergamon.

Clément, R. (1986). Second language proficiency and acculturation: An investigation of the effects of language status and individual characteristics. Journal of Language and Social Psychology, 5, 271-290.

Clément, R., Gardner, R. C., \& Smythe, P. C. (1977). Motivational variables in second language acquisition: A study of Francophones learning English. Canadian Journal of Behavioural Science, 9, 123-133.

Clément, R., Gardner, R. C., \& Smythe, P. C. (1980). Social and individual factors in second language acquisition. Canadian Journal of Behavioural Science, 12, 293302.

Clément, R., \& Kruidenier, B. G. (1986). The effect of context on the composition and role of orientations in second language acquisition. Ottawa, Canada: International Centre for Research on Bilingualism.

Costa, P. T., \& McCrae, R. R. (1985). The NEO Personality Inventory Manual. Odessa, FL: Psychological Assessment Resources.

Daly, J. (1991). Understanding communication apprehension: An introduction for language educators. In E. K. Horwitz \& D. J. Young (Eds.), Language anxiety: From theory and research to classroom implications (pp. 3-13). Englewood Cliffs, NJ: Prentice Hall.

Digman, J. M. (1980). Personality structure: Emergence of the five-factor model. Annual Review of Psychology, 41, 417-440.

Fazio, R. H. (1987). Self-perception theory: A current perspective. In M. P. Zanna, J. M. Olson, \& C. P. Herman (Eds.), Social influence: The Ontario Symposium (Vol. 5, pp. 129-150). Hillsdale, NJ: Lawrence Erlbaum. 
Funder, D. (1991). Global traits: A Neo-Allportian approach to personality. Psychological Science, 2, 31-39.

Gardner, R. C. (1980). On the validity of affective variables in second language acquisition: Conceptual, contextual and statistical considerations. Language Learning, 32, 255-269.

Gardner, R. C. (1985). Social psychology and second language learning: The role of attitudes and motivation. London: Edward Arnold.

Gardner, R. C. (1988). The socio-educational model of second language learning: Assumptions, findings and issues. Language Learning, 38, 101-126.

Gardner, R. C. (1991). Second language learning in adults: Correlates of proficiency. Applied Language Learning, 2, 1-28.

Gardner, R. C., Lalonde, R., \& Pierson, R. (1983). The socio-educational model of second language acquisition: An investigation using LISREL causal modelling. Journal of Language and Social Psychology, 2, 51-65.

Gardner, R. C., \& Lambert, W. E. (1972). Attitudes and motivation in second language learning. Rowley, MA: Newbury House.

Gardner, R. C., \& MacIntyre, P. D. (1992). A student's contributions to second language learning: Part I. Cognitive variables. Language Teaching, 25, 211-220.

Gardner, R. C., \& MacIntyre, P. D. (1993a). On the measurement of affective variables in second language learning. Language Learning, 43, 157-194.

Gardner, R. C., \& MacIntyre, P. D. (1993b). A student's contributions to second language learning. Part II. Affective variables. Language Teaching, 26, 1-11.

Goldberg, L. R. (1992). The development of markers for the big-five factor structure. Psychological Assessment, 4, 26-42.

Goldberg, L. R. (1993). The structure of phenotypic personality traits. American Psychologist, 48, 26-34.

Horwitz, E. K. (1986). Preliminary evidence for the reliability and validity of a foreign language anxiety scale. TESOL Quarterly, 22, 559-562.

Horwitz, E. K., Horwitz, M. B., \& Cope, J. (1986). Foreign language classroom anxiety. Modern Language Journal, 70, 125-132.

Horwitz, E. K., \& Young, D. J. (1991). Language anxiety: From theory and research to classroom implications. Englewood Cliffs, NJ: Prentice Hall.

Jöreskog, K., \& Sörbom, D. (1989). Lisrel 7 user's reference guide. Mooresville, IN: Scientific Software.

Koch, A. S., \& Terrell, T. D. (1991). Affective reactions of foreign language students to natural approach activities and teaching techniques. In E. K. Horwitz \& D. J. Young (Eds.), Language anxiety: From theory and research to classroom implications (pp. 109-126). Englewood Cliffs, NJ: Prentice Hall.

Krashen, S. (1981). Second language acquisition and second language learning. Toronto: Pergamon Press.

Lalonde, R. N., \& Gardner, R. C. (1984). Investigating a causal model of second language acquisition: Where does personality fit? Canadian Journal of Behavioural Science, 16, 224-237.

MacCallum, R. C., Roznowski, M., \& Necowitz, L. B. (1992). Model modifications in covariance structure analysis: The problem of capitalization on chance. Psychological Bulletin, 111, 490-504.

MacIntyre, P. D. (1992). Anxiety and language learning from a stages of processing perspective. Unpublished Doctoral Dissertation, University of Western Ontario, London, Canada.

MacIntyre, P. D. (1994). Variables underlying willingness to communicate: A causal analysis. Communication Research Reports, 11, 135-142.

MacIntyre, P. D., \& Gardner, R. C. (1989). Anxiety and second language learning: Toward a theoretical clarification. Language Learning, 39, 251-275. 
MacIntyre, P. D., \& Gardner, R. C. (1991a). Investigating language class anxiety using the focused essay technique. The Modern Language Journal, 75, 296-304.

MacIntyre, P. D., \& Gardner, R. C. (1991b). Language anxiety: Its relation to other anxieties and to processing in native and second languages. Language Learning, 41 , 513-534.

MacIntyre, P. D., \& Gardner, R. C. (1991c). Methods and results in the study of anxiety in language learning: A review of the literature. Language Learning, 41, 85-117.

Macintyre, P. D., \& Gardner, R. C. (1994a). The effects of induced anxiety on cognitive processing in second language learning. Studies in Second Language Acquisition, 16, $1-17$.

MacIntyre, P. D., \& Gardner, R. C. (1994b). The subtle effects of language anxiety on cognitive processing in the second language. Language Learning, 44, 283-305.

MacIntyre, P. D., \& Noels, K. A. (June, 1994). Communication apprehension, perceived competence, and actual competence in a second language. Presented at the annual conference of the Canadian Psychological Association, Penticton B.C.

McCrae, R. R., \& Costa, P. T. (1989). More reasons to adopt the five-factor model. American Psychologist, 44, 451-452.

McCroskey, J. C. (1977). Oral communication apprehension: A summary of recent theory and research. Human Communication Research, 4, 78-96.

McCroskey, J. C. (1984). The communication apprehension perspective. In J. A. Daly \& J. C. McCroskey (Eds.), Avoiding communication (pp. 13-38). Newbury Park, CA: Sage.

McCroskey, J. C. (1992). Reliability and validity of the willingness to communicate scale. Communication Quarterly, 40, 16-25.

McCroskey, J. C., \& Baer, J. E. (November, 1985). Willingness to communicate: The construct and its measurement. Paper presented at the annual convention of the Speech Communication Association, Denver.

McCroskey, J. C., \& McCroskey, L. L. (1986). Predictors of willingness to communicate: Implications for screening and remediation. Paper presented at the annual convention of the International Communication Association, Chicago, $\mathbb{L}$.

McCroskey, J. C., \& Richmond, V. P. (1987). Willingness to communicate. In J. C. McCroskey \& J. A. Daly (Eds.), Personality and Interpersonal Communication (pp. 129156). Newbury Park, CA: Sage.

McCroskey, J. C., \& Richmond, V. P. (1991). Willingness to communicate: A cognitive perspective. In M. Booth-Butterfield (Ed.), Communication, cognition, and anxiety (pp. 19-37). Newbury Park, CA: Sage.

McCroskey, J. C., Richmond, V. P., \& McCroskey, L. L. (1987). Correlates of self-perceived communication competence. Paper presented at the annual convention of the International Communication Association, Montreal.

Naiman, N., Frolich, M., Stern, H. H., \& Todesco, A. (1978). The good language learner. Research in education series, 7. Toronto: OISE.

Norman, W. T. (1963). Toward an adequate taxonomy of personality attributes: Replicated factor structure in peer nominated personality ratings. Journal of Abnormal and Social Psychology, 66, 574-583.

Oxford, R. (1991). Language learning strategies: What every teacher should know. New York: Newbury House.

Pritchard, D. F. (1952). An investigation into the relationship between personality traits and ability in modern languages. British Journal of Educational Psychology, 22, 147-148.

Richmond, V. P., \& McCroskey, J. C. (1985). Communication: Apprehension, avoidance and effectiveness. Scottsdale, AZ: Gorsuch Scarisbrick.

Segalowitz, N. (1976). Communicative incompetence and the non-fluent bilingual. Canadian Journal of Behavioural Science, 8, 122-131. 
Skehan, P. (1989). Individual differences in second language learning. London: Edward Arnold.

Smart, M., Elton, C. F., \& Burnett, C. W. (1970). Underachievers and overachievers in intermediate French. Modern Language Journal, 54, 415-442.

Swain, M., \& Burnaby, B. (1976). Personality characteristics and second language learning in young children: A pilot study. Working Papers on Bilingualism, 11, 115-128.

Zakahi, W. R., \& McCroskey, J. C. (1989). Willingness to communicate: A potentially confounding variable in communication research. Communication Reports, 2, 96-104. 